\title{
EFFECT OF ALKALINISATION OF URINE ON THE EFFICACY OF LEVOFLOXACIN IN URINARY TRACT INFECTION
}

\author{
Amit Kumar Ghosh', Mausumi De2, Saumya Sarkar ${ }^{3}$, Anup Kumar Das ${ }^{4}$ \\ ${ }_{1}^{1}$ Associate Professor, Department of Pharmacology, R. G. Kar Medical College. \\ ${ }^{2}$ Associate Professor, Department of Pharmacology, R. G. Kar Medical College. \\ ${ }^{3}$ Demonstrator, Department of Pharmacology, R. G. Kar Medical College. \\ 4 Professor and HOD, Department of Pharmacology, R. G. Kar Medical College.
}

\section{ABSTRACT}

\section{BACKGROUND}

In urinary tract infection, levofloxacin is used to treat both complicated and uncomplicated cases. To reduce the pain and burning sensation in lower UTI, physicians commonly prescribe an alkaliniser like disodium hydrogen citrate along with levofloxacin. The combined effect of these two drugs is unknown.

Aim of our study was to find out the effect of alkalinisation of urine on the efficacy of levofloxacin in uncomplicated urinary tract infection.

Study Design- The study was conducted at general screening outpatient department of R. G. Kar Medical College and Hospital. The study was a randomised assessor-blind study.

\section{MATERIALS AND METHODS}

Patients with symptoms of lower UTI were randomised and divided into two groups A and B. Group A were prescribed levofloxacin $250 \mathrm{mg}$ once daily for 3 days and group B were prescribed levofloxacin $250 \mathrm{mg}$ once daily for three days along with disodium hydrogen citrate $10 \mathrm{~mL}$ thrice daily for 3 days. Before prescribing the drugs, urine sample was sent for routine and culture sensitivity test.

Statistical Analysis Used- We applied Pearson's method.

\section{RESULTS}

In our study, it is found that levofloxacin $250 \mathrm{mg}$ daily for 3 days can eradicate the urinary pathogens in $93 \%$ of cases, but when levofloxacin is combined with disodium hydrogen citrate, it can eradicate only $70 \%$ of uropathogens in uncomplicated cases of lower UTI. The possible explanation of this reduced action of levofloxacin is that alkali solution may prevent the absorption of levofloxacin from stomach or levofloxacin may precipitate in alkaline urine or both. So the minimum inhibitory concentration (MIC) for antibacterial activity of levofloxacin cannot be reached in urine. Our conclusion is that levofloxacin should not be prescribed with alkali solution to treat UTI.

\section{CONCLUSION}

So we may conclude from this study that levofloxacin should not be combined with alkali mixture in the treatment of UTI.

\section{KEYWORDS}

Levofloxacin, Disodium Hydrogen Citrate, Urinary Tract Infection.

HOW TO CITE THIS ARTICLE: Ghosh AK, De M, Sarkar S, et al. Effect of alkalinisation of urine on the efficacy of levofloxacin in urinary tract infection. J. Evolution Med. Dent. Sci. 2016;5(96):7064-7067, DOI: 10.14260/jemds/2016/1598

\section{BACKGROUND}

Urinary tract infection (UTI) is a very common disease affecting all age groups and specially in females due to its anatomical and physiological conditions. Treatment of UTI has posed to be a problem to the clinician due to emergence of resistance strains of bacteria to various antimicrobials used over the years. Quinolones are very much effective in the

Financial or Other, Competing Interest: None.

Submission 27-10-2016, Peer Review 20-11-2016,

Acceptance 26-11-2016, Published 01-12-2016.

Corresponding Author:

Dr. Amit Kumar Ghosh,

Associate Professor,

Department of Pharmacology,

R. G. Kar Medical College, Kolkata, India.

E-mail: dyregistraramitghosh@gmail.com

DOI: $10.14260 /$ jemds/2016/1598 treatment of UTI and newer quinolones are very much sensitive to these pathogenic organisms.

In the treatment of UTI, alkalinisation of urine is a common practice because this reduces the pain and burning sensation during voiding1. Levofloxacin a well-known fluoroquinolone (Figure 1) often used for the treatment of UTI, is found to be effective in most of the cases of uncomplicated UTI. ${ }^{2}$ However, when levofloxacin is combined with disodium hydrogen citrate, a urinary alkalinising solution, in treatment of UTI the outcome may change, but there is no clinical and pharmacokinetic data available regarding the outcome of this combination in our population. ${ }^{3}$ This present study was carried out to assess the effect of alkalinisation of urine on the efficacy of levofloxacin, a newer fluoroquinolone in the treatment of uncomplicated UTI. The clinical response was evaluated only in patients with symptoms and signs of lower urinary tract infections. ${ }^{4}$ 


\section{MATERIALS AND METHODS}

Patients were mostly recruited from the out-patient department (general screening OPD) of R. G. Kar Medical College, Kolkata. Permission from institutional ethics committee of R. G. Kar Medical College was taken prior to starting the study.

Patients with uncomplicated UTI aged between 15 to 45 years were included in the study. Exclusion criteria were pregnant and lactating mothers, any haematological diseases, diabetes mellitus (Type $1 \& 2$ ), malignancy, any urinary tract abnormality, known liver/kidney/cardiac disorders, known allergy to fluoroquinolones and history of any other antibiotic intake within 2 weeks prior to study and also during study period.

\section{Methods}

After recruitment, a detailed medical history was taken followed by thorough clinical examinations which include both general and systemic examination. These were followed by examination of urine i.e. routine urine examination $(\mathrm{pH}$, pus cells, RBC, epithelial cells, albumin, sugar, casts) with culture and sensitivity test. Common laboratory investigations $(\mathrm{Hb} \%$, TC, DC, ESR, FBS, urea, creatinine, Liver function test) and imaging (Straight x-ray abdomen/KUB, Ultrasonography) were done mainly in selected cases.

The patients with UTI were screened from OPD with one or more of the following criteria: dysuria, increased frequency of urination, decreased amount of urine passed, high coloured or red urine, fever, suprapubic tenderness. Following the above inclusion and exclusion criteria, 80 patients were included in the study in a randomised way among the patients of UTI found during the study periods.

The study is a randomised and assessor blind study. Randomisation were done using randomisation table. After screening, the patients fulfilling the selection criteria except the culture sensitivity report (Which will be available after 72 hours) were randomised and first dose of study medication were given orally on this $1^{\text {st }}$ day of visit. A mid-stream urine specimen was obtained at baseline for routine analysis and for culture \& sensitivity testing before ingestion of the drug. On next visit, at $3^{\text {rd }}$ day of treatment, clinical evaluation was done as well as bacteriological tests were repeated in all patients. Those with persistence of symptoms, another course of levofloxacin $250 \mathrm{mg}$ once daily for another 3 days were given. Bacteriological and clinical effectiveness reassessed on $7^{\text {th }}$ day.

\section{Treatment Modality}

The patients were put into the following two groups on the basis of treatment pattern irrespective of types of uropathogen detected. First group consisted of 40 patients who were treated with levofloxacin in doses of $250 \mathrm{mg}$ once daily for 3 days. The second group of 40 patients were treated with levofloxacin in doses of $250 \mathrm{mg}$ OD and alkali solution (disodium hydrogen citrate $1.4 \mathrm{~g} / 5 \mathrm{~mL}$ ) $10 \mathrm{~mL}$ thrice daily for 3 days. ${ }^{5}$ Patients were evaluated bacteriologically and clinically accordingly and statistical analysis by chi square test.

\section{RESULTS}

Among the 80 patients in the study, 76 were female and 4 were male. Their mean age was 32 years and average body weight was $56 \mathrm{~kg}$. The commonest symptom was dysuria followed by increased frequency. Many clinically diagnosed cases of UTI were excluded from our study when results of urinalysis were negative for microscopical as well as culture.

Analysis of the clinical and bacteriological findings of these cases who had urinary symptoms were done. The results were shown in table 1.

\section{Result of Culture of Urine}

All the 80 cases were diagnosed as cases of UTI on the basis of culture, Pus cells and Bacteria obtained from urine of the patients. The various organisms isolated from the urine culture were as follows: Escherichia coli 73 cases, Klebsiella 3 cases, Pseudomonas 3 cases and Proteus 1 case given in the following table 2 .

This table shows that Escherichia coli was the most common organism isolated from urine samples and Proteus is the least one.

\section{Result of Treatment}

All our study population received levofloxacin empirically. Clinical and bacteriological evaluations were done after 3 days of therapy. It is seen that the 40 cases treated with Levofloxacin alone, 37 were clinically cured (93\%) and in the other group of 40 patients treated with Levofloxacin and alkali solution cure rate was (70\%) 28 cases.

Cases were designated bacteriologically as eradicated, when urine samples were found to be sterile and persistent when the urine specimens showed bacteria microscopically or growth on culture or both. This is shown in table 3 .

It was seen that after 3 days of therapy, eradication is $93 \%$ with Levofloxacin alone and only 70\% with Levofloxacin+ alkali solution.

\section{Result of Retreatment}

Those 12 cases which were not eradicated by Levofloxacin plus alkali solution treatment for 3 days were again subjected to another 3 days' therapy with levofloxacin $250 \mathrm{mg}$ alone. It is seen that out of 12 patients, 10 cases who failed to show eradication by treatment with levofloxacin with alkali solution could be eradicated by another 3 days' therapy with levofloxacin alone. It is also seen that three (03) cases in group A and two (02) patients in group B failed to another 3 days therapy with $250 \mathrm{mg}$ levofloxacin and they were prescribed another antibiotic.

\section{Bacteriological Outcome in Vitro}

All the microorganisms isolated in Macon key's culture medium were moderate to highly sensitive to levofloxacin $5 \mathrm{mcg} /$ bio-disc.

\section{Statistical Analysis}

Finding the p-value with Pearson's two-sided Chi-square comparison, we found the significance of difference of clinical outcome results between levofloxacin (Group A) and levofloxacin+alkali solution (Group B). The $\mathrm{p}$ value was $\mathrm{p}<0.001$ which denotes that the observation is statistically significant. 


\begin{tabular}{|c|c|c|c|c|c|c|c|c|c|}
\hline \multirow[t]{2}{*}{$\begin{array}{c}\text { Nature of } \\
\text { Symptoms }\end{array}$} & \multirow[t]{2}{*}{\begin{tabular}{|c|} 
No. of Cases \\
(+VE) Findings
\end{tabular}} & \multirow{2}{*}{$\begin{array}{c}\text { Microscopical } \\
\text { Urinary Finding } \\
+\mathrm{VE}\end{array}$} & & \multicolumn{6}{|c|}{$\begin{array}{l}\text { Microscopical, Bacteriological } \\
\text { and Culture in Positive Cases }\end{array}$} \\
\hline & & & $-\mathrm{VE}$ & $\mathrm{P}$ & $\mathrm{B}$ & $\mathrm{P}+\mathrm{B}$ & $\mathrm{P}+\mathrm{C}$ & $\mathrm{B}+\mathrm{C}$ & $\mathrm{P}+\mathrm{B}+\mathrm{C}$ \\
\hline Dysuria & 31 & 26 & 5 & 6 & 8 & 3 & 2 & 3 & 4 \\
\hline Increased Frequency of Urination & 15 & 10 & 5 & 3 & 3 & 1 & 1 & 1 & 1 \\
\hline Pain in Lower Abdomen & 13 & 10 & 3 & 2 & 2 & 2 & 1 & 0 & 3 \\
\hline Dysuria+Increased Frequency & 7 & 7 & 0 & 2 & 1 & 1 & 1 & 1 & 1 \\
\hline Dysuria+Fever & 5 & 5 & 0 & 2 & 0 & 0 & 0 & 1 & 2 \\
\hline Fever+Frequency & 5 & 4 & 1 & 1 & 1 & 0 & 0 & 1 & 1 \\
\hline Dysuria+Frequency+Fever & 3 & 3 & 0 & 0 & 0 & 0 & 0 & 1 & 2 \\
\hline High Colour Urine & 1 & 1 & 0 & 0 & 0 & 0 & 0 & 0 & 1 \\
\hline
\end{tabular}

$\mathrm{P}=$ PUS Cells, $\mathrm{B}=$ Bacteria, $\mathrm{C}=$ Culture

\begin{tabular}{|c|c|c|}
\hline Organisms & No. of Cases & Percentage \\
\hline E. Coli & 73 & 91.25 \\
\hline Klebsiella & 3 & 3.76 \\
\hline Pseudomonas & 3 & 3.76 \\
\hline Proteus & 1 & 1.25 \\
\hline Total & 80 & 100 \\
\hline
\end{tabular}

\begin{tabular}{|c|c|c|c|}
\hline Treatment & $\begin{array}{l}\text { No. of } \\
\text { Cases }\end{array}$ & Eradication & $\begin{array}{c}\text { No. of Cases } \\
\text { Persistent }\end{array}$ \\
\hline $\begin{array}{c}\text { Levofloxacin Alone } \\
\text { (GR-A) }\end{array}$ & 40 & 37 (93\%) & $3(7 \%)$ \\
\hline $\begin{array}{c}\text { Levofloxacin+ } \\
\text { Alkali Solution (GR-B) }\end{array}$ & 40 & $28(70 \%)$ & $12(30 \%)$ \\
\hline Total & 80 & 65 (81\%) & $15(37 \%)$ \\
\hline
\end{tabular}

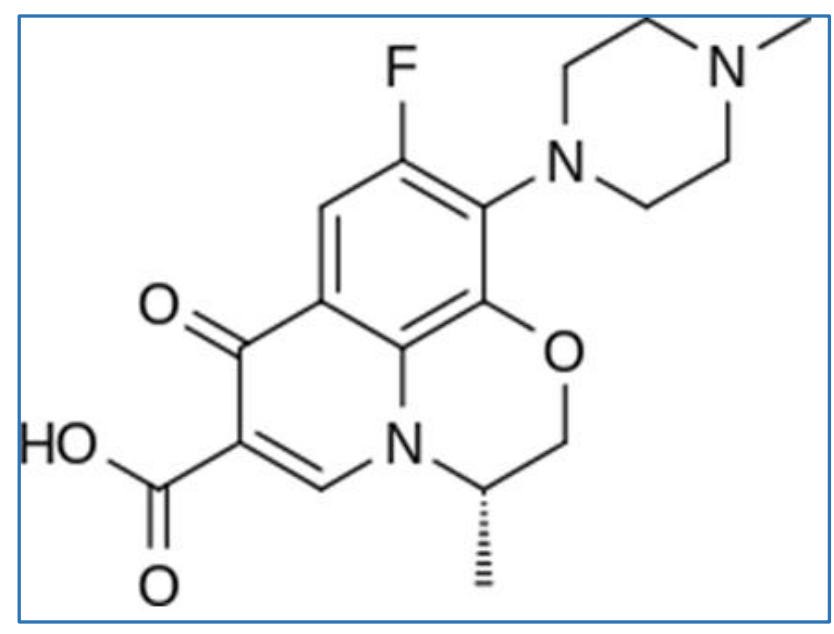

Figure 1. Chemical Structure of Levofloxacin

\section{DISCUSSION}

Urinary tract infection is a common disease affecting predominantly females between ages of 15 to 45 years. In this study, also got female: male ratio is 19:1. Among males most of the UTIs are secondary to some organic defects like Posterior Urethral Valve, stricture urethra, Benign Prostatic Hyperplasia, etc. Some cases of UTI were found secondary to metabolic disorders like diabetes and all these cases were excluded from our study.

The present comparative study of bacteriological and clinical efficacy showed that 93\% (37/40) of patients were relieved of symptoms and signs when levofloxacin was used alone (Group A), whereas only 70\% (28/40) of patients who received levofloxacin+alkali mixture (group B) showed eradication and clinical cure. In the group $B$ patients whom eradication failed $(12 / 40)$, they were prescribed further treatment of 3 days of levofloxacin and showed $88 \%$ eradication of the organism. Therefore, we can say that antibacterial efficacy of levofloxacin in vivo is reduced in the presence of alkalinisation of urine.

There is no specific explanation of this reduced efficacy of levofloxacin in presence of alkali mixture. It is postulated that when levofloxacin is taken with antacids containing magnesium hydroxide or aluminium hydroxide, these two combine to form insoluble salts that are difficult to absorb from the intestines. Peak serum concentrations of levofloxacin may be reduced by $90 \%$ or more, which can prevent the levofloxacin from working.6,7 However, no specific pharmacokinetic or pharmacodynamics, drug-drug interaction between levofloxacin and disodium hydrogen citrate was found in any literature.

Levofloxacin is the levo isomer of the racemate ofloxacin, this means that levofloxacin is the $50 \%$ of ofloxacin been found to be effective against bacteria, while the other $50 \%$ is inactive. In chemical terms, levofloxacin, a chiral fluorinated carboxyquinolone, is the pure $(-)-(\mathrm{S})$-enantiomer of the racemic ofloxacin. 8

Lacely et al (1987) observed the presence of crystals of fluoroquinolones particularly of Norfloxacin in the alkaline urine. This may also occur following administration of levofloxacin with alkali mixture.

Following oral administration, $87 \%$ of an administered dose was recovered in the urine as unchanged drug within 2 days. Less than $5 \%$ was recovered in the urine as the desmethyl and $\mathrm{N}$-oxide metabolites, the only metabolites identified in humans. So, elimination of levofloxacin occurs mainly via excretion of unmetabolised drug in the urine in its active form. ${ }^{9}$ It is known that an antibacterial used to treat UTI need to be excreted in adequate concentrations in urine (Sean, 2007). Thus, the amount of levofloxacin excreted via urine is adequate to treat uncomplicated UTI in most of the cases and in a very small dose (250 $\mathrm{mg}$ for 3 days) but due to alkalinisation of urine most of the drug may crystallise and amount of active drug in urine may be less for its antibacterial activity. Due to the above reasons, the concentration of levofloxacin and its active metabolite in alkaline urine may be less than the required minimum inhibitory concentration.

\section{CONCLUSION}

So we may conclude from this study that levofloxacin should not be combined with alkali mixture in the treatment of UTI. 


\section{REFERENCES}

1. Sweetman SC. Martindale: the complete drug reference. 36th edn. UK: Pharmaceutical Press 2009:p. 199.

2. Meng MV, Stoller ML, Walsh T. Urologic disorder. In: Mcphee SJ, Papadakis MA, eds. Current medical diagnosis and treatment, 49 ${ }^{\text {th }}$ edn. New York: McGraw-Hill 2010:p. 851.

3. Kamberi M, Kotegawa T, Tsutsumi K, et al. Sparfloxacin pharmacokinetic in healthy volunteers: the influence of acidification and alkalinisation. Eur J Clin Pharmacol 1998;54(Suppl 8):633-40.

4. Walter E. Stamm urinary tract infection, pyelonephritis, and prostatitis. In: Fauci A, Braunwaid E, Kasper D, et al, eds. Harrison's principles of internal medicine. 17th edn. New York: McGraw-Hill 2008:p. 1820.

5. Sweetman SC. Martindale: the complete drug reference. 36th edn. UK: Pharmaceutical Press 2009:p.289.
6. Rodvold KA, Piscitelli SC. New oral macrolide and fluoroquinolone antibiotics: an overview of pharmacokinetics, interactions, and safety. Clin Infect Dis 1993;17(Suppl 1):S192-9.

7. Tanaka M, Kurata T, Fujisawa C, et al. Mechanistic study of inhibition of levofloxacin absorption by aluminium hydroxide. Antimicrob Agents Chemother 1993;7(10):2173-8.

8. Domagala JM. Structure-activity and structure-side-effect relationships for the quinolone antibacterials. J Antimicrob Chemother 1994;33(4):685-706.

9. Morrissey I, Hoshino K, Sato K, et al. Mechanism of differential activities of ofloxacin enantiomers.(PDF). Antimicrob Agents Chemother 1996;40(8):1775-84. 